\title{
スプール弁等価負重合量の一間接測定法*
}

\author{
荒木 獻 次**
}

\section{An Indirect Measurement of the Equivalent Underlaps of a Spool Valve}

\author{
Kenji ARAKI
}

Laps of a spool valve have a large effect not only on the characteristics of the valve itself but also on the ones of a valve-controlled actuator system. However, there may be no report on the measurements of valve laps. The spools of actual valves, such as servovalves, are not always machined so accurately. While a valve is being used, it wears, and the clearance between the spool land and the sleeve may become larger and/or its sharp edges may be deformed to some extent and thus its equivalent laps may change. The laps of such a valve have not been defined yet. It is very difficult and impractical to measure the shapes of a spool and a sleeve directly.

The author has defined the equivalent laps of an actual valve as the laps of an underlap valve which has the accurate sleeve ports and spool lands dimenstions and has almost the same characteristics as the actual valve for some certain range. An indirect method to measure the equivalent underlaps of a valve is proposed, where the pressure characteristics of the valve are used. The underlaps of two actual valves were easily measured by indirect method.

\section{1.はしがき}

スプール弁の重合量は弁自体の特性のみならず弁・ アクチュエータ系の特性に大きな影響を及ぼす1) -3). しかし, 弁重合量の測定に関する研究報告はないよう である、実際のスプール弁は，必ずしも理想的にでき ている弁とは見なし難い。また使用しているうちに弁 が摩耗して, スプールとスリーブの直径が変化したり, “だれ”を生じて，その重合量が変化することはしば しばある. 重合量は，これまで理想的な弁についての み定義されており4)，スプール・スリーブ間の間隙が無 視できない弁や,摩耗などによるシャープエッジに゙だ れ”のある弁については定義されていない. また，そ のような重合量を定義しえたとしても，製品の弁形状 を直接測定して重合量を求めることは，困難なことで あり，現実味に欠ける。

ここでは，ある範囲で実際の弁に近い特性を示す理 想的な弁の重合量をもって，その弁の等価重合量と考 えることにし, 空気圧を用いてスプール弁圧力特性を

\footnotetext{
*昭和63年 1 月 21 日 原稿受付

***埼玉大学工学部

(所在地 $\bar{\top} 338$ 浦和市下大久保255)
}

実測し，その弁の等価負重合量を間接的に測定する方 法について述べる. また,この測定法を二種類の弁に 適用し，等価負重合量が比較的容易に測定できること を示した。

\section{2. 理想的な負重合弁の特性と等価負重合量}

等価負重合量の基準を, 理想的な負重合弁の特性に おくので, その理想的な弁の特性を調べておく必要が ある. 弁特性としては, 弁変位に対する圧力特性と流 量特性とが考えられるが, ここでは測定容易な圧力特 性を用いることにする。サーボ弁においては，ヒステ リシスがなければ，弁変位の代りに電気信号を用いて もよい.

Fig. 1 は理想的な負重合弁 (以後, 理想弁と略称す る）であり両負荷ポートは閉栓されている。ここで, 理想的な弁とは, 制御オリフィス部のシャープエッジ にだれがなく，スプール・スリーブの間隙が無視でき るものと考えることにする， $\Delta_{1}, \Delta_{2}, \Delta_{1}{ }^{\prime}$ おび゙ $\Delta_{2}{ }^{\prime}$ は 負重合量, $p_{\mathrm{s}}, p_{\mathrm{d}}, p_{\mathrm{L}}$ および $p_{\mathrm{L}}{ }^{\prime}$ は, それぞれ供給圧, 戻り圧（排気圧）抢よび左右ポート圧である。右側三 方弁の記号または変数には印をつける。スプール変位 $y$ は中立 $\left(p_{\mathrm{L}}=p_{\mathrm{L}}{ }^{\prime}\right)$ からの右向き変位とする，測定に際 してはゲージ圧を用いるのが便利である。ゲージ圧を 


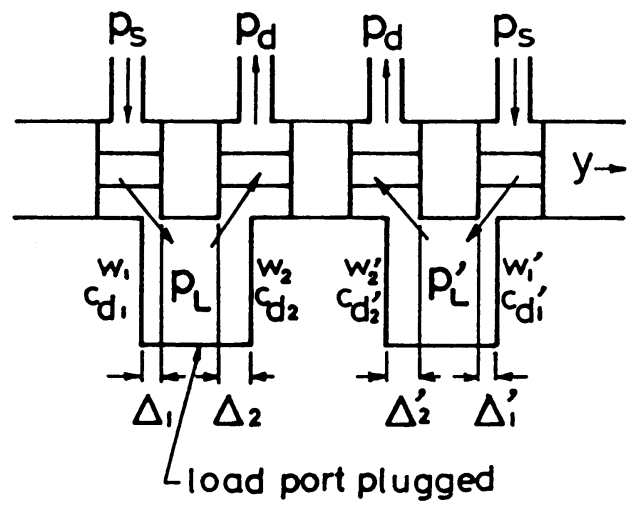

Fig. 1 Four-way valve with uneven-underlaps which is ideally made.

表すのに， $p_{\mathrm{SG}}, p_{\mathrm{LG}}, \mathrm{KPaG}$ ように添え字や単位にG を付けることにする。

\section{1 理想弁の圧力特性}

Fig. 1の理想弁において, 流量係数を $c_{d 1}=c_{d 2} \equiv c_{d}{ }^{*}$ および排気圧を $p_{d}=p_{e}$ （大気圧 $=101.3 \mathrm{kPa}$ ）と仮定す

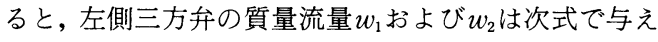
られる3).

$$
\begin{aligned}
& w_{1}=F f\left(\Delta_{1}+y\right) \quad h_{1} \\
& w_{2}=F f\left(\Delta_{2}-y\right) \quad h_{2} \\
& F=c_{d} b_{p} \sqrt{\frac{2 \varkappa}{\varkappa-1} \cdot \frac{\rho_{e}}{p_{e}}} p_{s} H \\
& f(x)= \begin{cases}x & (x>0) \\
0 & (x \leqq 0)\end{cases} \\
& H=\sqrt{\frac{\varkappa-1}{\varkappa+1}\left(\frac{2}{\varkappa+1}\right)^{2 /(\varkappa-1)}} \\
& h_{1}=\left\{\begin{array}{lr}
\sqrt{p^{2 / x}-p^{(x+1) / x}} / H & (1 \geqq p>0.5283) \\
1 & (0.5283 \geqq p)
\end{array}\right. \\
& p=p_{L} / p_{s} \\
& h_{2}=\left\{\begin{array}{rr}
p^{(x+1) / 2 \times} \sqrt{p_{P}^{2 / x}-p_{P}^{(x+1) / x}} / H \\
\\
p^{(x+1) / 2 \times} \quad\left(1 \geqq p_{P}>0.5283\right) \\
\left(0.5283 \geqq p_{P}\right)
\end{array}\right. \\
& p_{P}=p_{e} / p_{s} p
\end{aligned}
$$

*本研究における三方弁のスプール移動範囲は, $-\Delta_{1}$ から+ $\Delta_{2}$ であるが, ここで着目するポート圧力pが ほぼ0.1psから0.9psの範囲なので, 上, 下流両ポー トはかなり開いている状態である。一般に，まだ寿 命のある三方弁の，スプール・スリーブ間の吵間, 両者の摩耗状況, 両者のシャープエッジのダレの形 状等が上，下流で著しく異なることはないと思われ るので，このように仮定しても，理論值と測定結果 との間にそれほど大きな相違を生じることはないも のと考えられる.

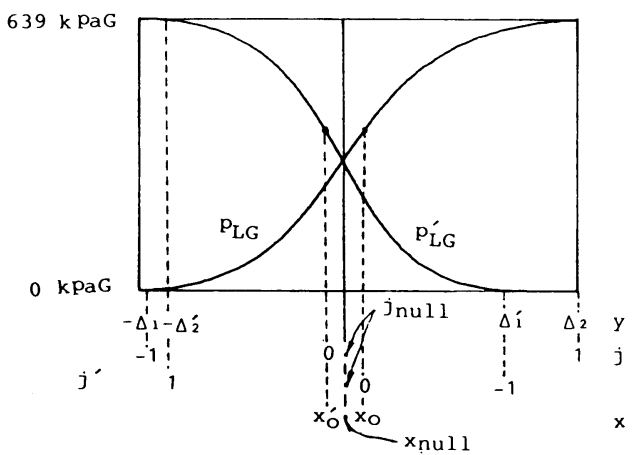

Fig. $2 p_{L G}$ vs.y and $p_{L G}^{\prime}$ vs.y characteristics of the valve shown in Fig. 1 (Theoretical $\left.p_{s G}=639 \mathrm{kPaG}\right)$

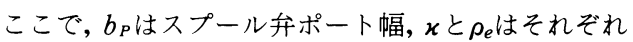
空気の比熱比と標準状態の密度である.制御オリフィ ス部分の流量は, その開き $f(x)$ に比例する. Fig. 1の 左側三方弁において, スプール変位 $y$ を十分ゆっくり 変化させると,

$$
w_{1}=w_{2}
$$

式(1)，(2)を式(7)に代入し，整理すれば，負荷ポート 圧 $p$ が次式のように求められる.

I $(S u b-s u b): \sqrt{\frac{p_{P}^{2 / x}-p_{P}^{(x+1) / x}}{p^{-(x-1) / x}-1}}$

$$
=\frac{\Delta_{1}+y}{\Delta_{2}-y}
$$

II $(\operatorname{Son}-s u b): p=\frac{p_{e}}{p_{s}}\left\{\left(H \frac{\Delta_{1}+y}{\Delta_{2}-y}\right)^{2}\right.$

$$
\left.\left(\frac{p_{e}}{p_{s}}\right)^{-(x+1) / x}+1\right\}^{* /(x-1)}
$$

III $($ Son-son $): p=\left(\frac{\Delta_{1}+y}{\Delta_{2}-y}\right)^{2 \times /(\varkappa+1)}$ (10)

IV $(S u b-\operatorname{son}): p$

$$
=\left\{\left(H \frac{\Delta_{2}-y}{\Delta_{1}+y}\right)^{2}+1\right\}^{-x /(x+1)} \text { (11) }
$$

ここで，I（Son-sub）は上流側の制御オリフィス 部流速が音速，下流側が亜音速であることを示す．II からIVについても同様である。

右側三方弁の負荷ポート圧 $p_{L}{ }^{\prime}$ も同様に導ける.すな わち,

$$
\begin{aligned}
& \text { 式(8)-(11)において, } p, \Delta_{1}+y \text { および } \\
& \Delta_{2}-y \text { をそれぞれp } p^{\prime}, \Delta_{1}^{\prime}-y \\
& \text { および } \Delta_{2}{ }^{\prime}+y に \text { 置き換えた式 }
\end{aligned}
$$

$p_{s}, \Delta_{1}, \Delta_{2}, \Delta_{1}{ }^{\prime}, \Delta_{2}{ }^{\prime}$ おび $y$ が与えらたとき, $\mathrm{p}_{\mathrm{L}}$ および $\mathrm{p}_{\mathrm{L}}{ }^{\prime}$ が式(8)〜(12)より算出される.

Fig. 2 は $p_{s G}=639 \mathrm{kPaG}$ の場合の圧力特性の一例で 
ある. $y=-\Delta_{1}$ および $\Delta_{1}{ }^{\prime}$ で, それぞれ $p_{L G}=p_{L G}{ }^{\prime}=0$ と なり, $y=\Delta_{2}$ およびー $\Delta_{2}{ }^{\prime} て ゙, そ れ そ ゙ れ p_{L G}=p_{L G}{ }^{\prime}=p_{G}$ となる。

\section{2 等価負重合量の一推定法}

Fig. 3 は，ある供給圧における理想弁の圧力特性 ( $p_{L G}-y$ 特性) を実線で示し, それに対応する実測值

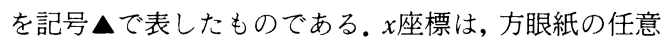
に定めた原点 0 から直線目盛り（例えば $\mathrm{cm} ）$ で右向き にとる. j座標は, $y=-\Delta_{1}$ おび $\Delta_{2}$ において, それぞ れー 1 および 1 となる直線座標である。

Fig. 1 の左右三方弁の平均負重合量 $\Delta お よ ひ ゙ \Delta^{\prime}$ は,

$$
\Delta=\frac{\Delta_{1}+\Delta_{2}}{2}, \quad \Delta^{\prime}=\frac{\Delta_{1}{ }^{\prime}+\Delta_{2}{ }^{\prime}}{2}
$$

で与えられる。また，Fig. 3において，

$j=0$ に対応する $x$ 座標を $x=x_{0}$

とおくと, $x$ と $j$ と間には次の関係がある.

$$
K_{d}\left(x-x_{0}\right)=j \Delta
$$

ここで,

$$
K_{d}=\frac{(\text { スプール変位 } \mu \mathrm{m})}{(\text { グラフ目盛 } \mathrm{cm})}
$$

また，次の関係がある。

$$
\begin{aligned}
& j=1 \text { で } x=x_{\Delta}=x_{0}+\frac{\Delta}{K_{d}} \\
& j=-1 \text { で } x=x-\Delta=x_{0}-\frac{\Delta}{K_{d}}
\end{aligned}
$$

いま, Fig. 3 において, $p_{L G_{1}}$ と $p_{L G m}$ の間を $(m-1)$ 等分し, それらの值を $p_{L G_{1}}, p_{L G_{2}}, \cdots \cdots p_{L G_{m}}$ とおく. それらに対応する $x$ 座標と $j$ 座標の值を, それぞれ $x_{1}$, $x_{2}, \cdots \cdots x_{m}$ および $j_{1}, j_{2}, \cdots \cdots j_{m}$ とする.

ここで

$$
E=\sum_{K}\left[K_{d}\left(x_{K}-x_{0}\right)-j_{K} \Delta\right\rceil^{2}
$$

$$
\text { （ } \sum_{K} \text { は } \sum_{K=1}^{m} \text { を意味する） }
$$

を最小にする， $\Delta$ と $x_{0}$ を求める。すなわち，

$$
\frac{\partial E}{\partial \Delta}=-2 \sum_{K} K_{d}\left(x_{K}-x_{0}\right) j_{K}+2 \Delta \sum_{K} j_{K}^{2}=0
$$

$$
\frac{\partial E}{\partial x_{0}}=-2 K_{d} \sum_{n} K_{d}\left(x_{n}-x_{0}\right)+2 K_{d} \Delta \sum_{n} j_{n}=0,
$$

$$
\text { （ } \sum_{n} \text { は } \sum_{n=1}^{m} \text { を意味する） }
$$

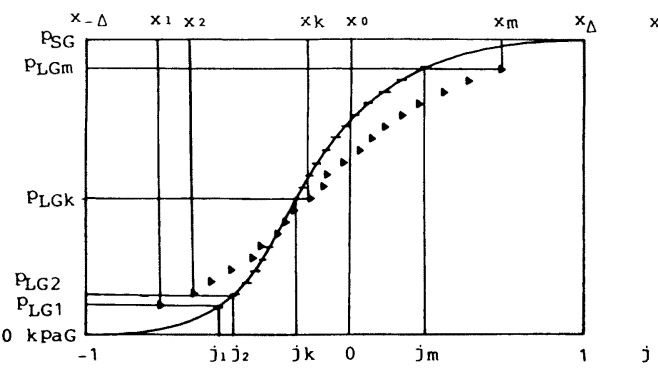

Fig. 3 Diagram to obtain $\Delta$ and $x_{0}$ from the theoretical curve and measured data of the left three-way valve

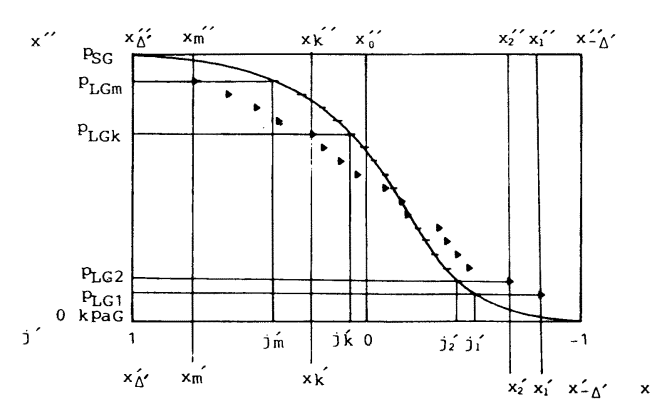

Fig. 4 Diagram to obtain $\Delta^{\prime}$ ans $x_{0}^{\prime}$ from the theoretical curve and measured data of the right three-way valve

$$
x_{0}=\frac{1}{m} \sum_{n} x_{n}-\frac{\Delta}{K_{d} m} \sum_{n} j_{n}
$$

式(21)を式(20)に代入すると，

$$
\Delta=\frac{m \sum_{K} K_{d} x_{K} j_{K}-\sum_{n} K_{d} x_{n} \sum_{K} j_{K}}{m \sum_{K} j_{K}^{2}-\left(\sum_{K} j_{K}\right)^{2}}
$$

また，式(23)を式(22)に代入すると，

$$
x_{0}=\frac{\sum_{n} x_{n} \sum_{K} j K^{2}-\sum_{K} x_{K} j_{K} \sum_{n} j_{n}}{m \sum_{K} j_{K}{ }^{2}-\left(\sum_{K} j_{K}\right)^{2}}
$$

また, Fig. 1 の右側三方弁の圧力特性をFig. 4 に示 す. $x^{\prime \prime}$ 軸と $j^{\prime}$ 軸を左向きにとる， $p_{L G_{1}}, p_{L G m}$ の間を $(m-1)$ 等分した值 $p_{L G_{1}}, p_{L G_{2}}, \cdots \cdots p_{L G m}$ に対応する

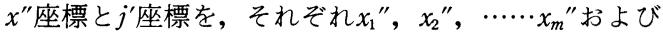
$j_{1}{ }^{\prime}, j_{2}{ }^{\prime}, \cdots \cdots j_{m}{ }^{\prime}$, また, 右向きの $x$ 座標を $x_{1}{ }^{\prime}, x_{2}{ }^{\prime}, \cdots \cdots$ $x_{m}^{\prime}$ とする. Fig. 4 において， $j^{\prime}=0$ に対応する $x^{\prime \prime}$ 座標を

$$
x^{\prime \prime}=x_{0}{ }^{\prime \prime}, x \text { 座標を } x=x_{0}{ }^{\prime}
$$


とおくと, $x^{\prime \prime}$ と $j^{\prime}$ との間に次の関係がある.

$\left.\begin{array}{l}K_{d}\left(x^{\prime \prime}-x^{\prime \prime}{ }_{0}\right)=j^{\prime} \Delta^{\prime} \\ K_{d}\left(x_{0}{ }^{\prime}-x^{\prime}\right)=j^{\prime} \Delta^{\prime} \text { または } x^{\prime}=x_{0}{ }^{\prime}-\frac{\Delta^{\prime}}{K_{d}} j^{\prime}\end{array}\right\}$

ここで,

$j^{\prime}=1$ でx'= $x^{\prime} \Delta^{\prime}=x_{0}^{\prime}-\frac{\Delta^{\prime}}{k_{d}}$

$j^{\prime}=1$ でx $=x^{\prime}-\Delta^{\prime}=x_{0}{ }_{0}+\frac{\Delta^{\prime}}{k_{d}}$

また，ここで，左側三方弁の場合と同様に，

$E^{\prime}=\sum_{K}\left[K_{d}\left(x_{K}^{\prime \prime}-x_{0}{ }^{\prime}\right)-j^{\prime}{ }_{K} \Delta^{\prime}\right]^{2}$

$$
=\sum_{K}\left[-K_{d}\left(x^{\prime}{ }_{K}-x_{0}^{\prime}\right)-j_{K^{\prime}} \Delta^{\prime}\right)^{2}
$$

を最小にする， $\Delta^{\prime} と x_{0}^{\prime}$ を求めると，

$$
\begin{aligned}
\Delta^{\prime} & =-\frac{m \sum_{K} K_{d} x^{\prime}{ }_{K} j^{\prime}{ }_{K}-\sum_{n} K_{d} x^{\prime}{ }_{n} \sum_{K} j^{\prime}{ }_{K}}{m \sum_{K} j^{\prime}{ }^{2}-\left(\sum_{K} j^{\prime}{ }_{K}\right)^{2}} \\
x_{0}^{\prime} & =\frac{1}{K_{d} m} \sum_{n} K_{d} x_{n}+\frac{\Delta}{K_{d} m} \sum_{n} j_{n}{ }^{\prime} \\
& =\frac{\sum_{n} x^{\prime}{ }_{n} \sum_{K} j^{\prime}{ }^{2}-\sum_{K} x^{\prime}{ }_{K} j_{K}{ }^{\prime} \sum_{n} j_{n}{ }^{\prime}}{m \sum_{K} j^{\prime}{ }^{2}-\left(\sum_{K} j^{\prime}{ }_{K}\right)^{2}}
\end{aligned}
$$

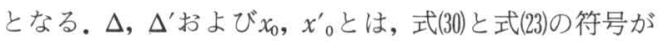
異なる点を除けば似た形の式で表される. Fig. 2 の $p_{L G}$ と $p_{L G}$ が交わる点すなわち弁の中立に扔ける $x$ と の値を $x_{\text {null }}$ および $j_{\text {null }}$ とおく. Fig. 2 において, $p_{L} c^{\prime}$ 曲 線の $x_{\text {nul }}$ を通る縦線に対する線対称図形を作り， $x_{\text {null }}$ の点を動かさずに, 横方向に $\Delta / \Delta^{\prime}$ 倍すると, $p_{L G}$ 曲線に 完全に重なることから，

$$
\frac{x_{\text {null }}-x_{0}}{x_{\text {null }}-x_{0}^{\prime \prime}}=\frac{2 \Delta}{2 \Delta^{\prime}}=\frac{x_{\text {null }}-x_{0}}{x_{0}^{\prime}-x_{\text {null }}}
$$
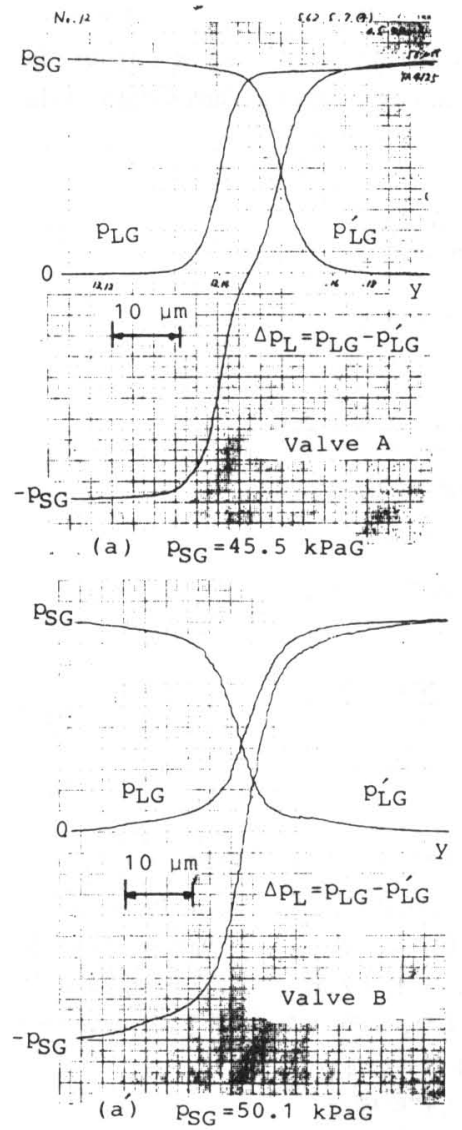
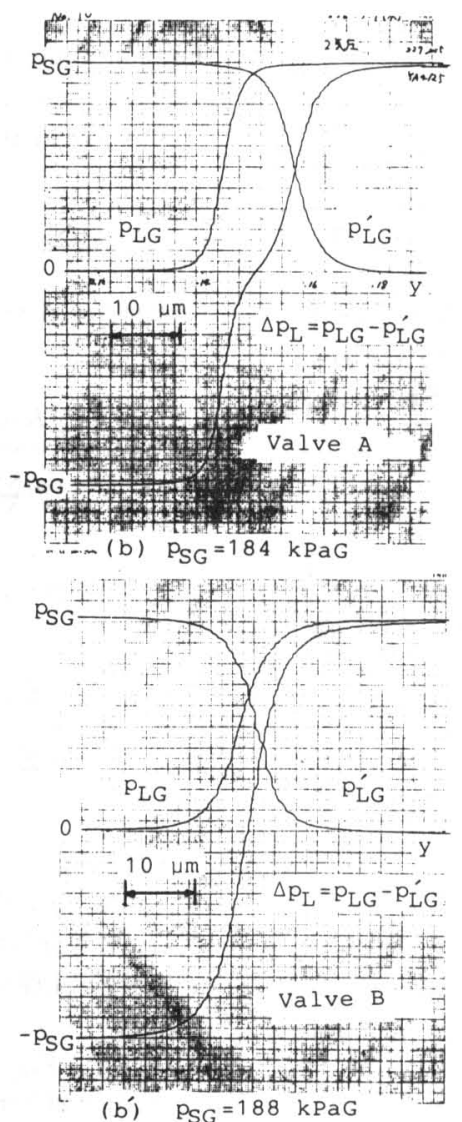
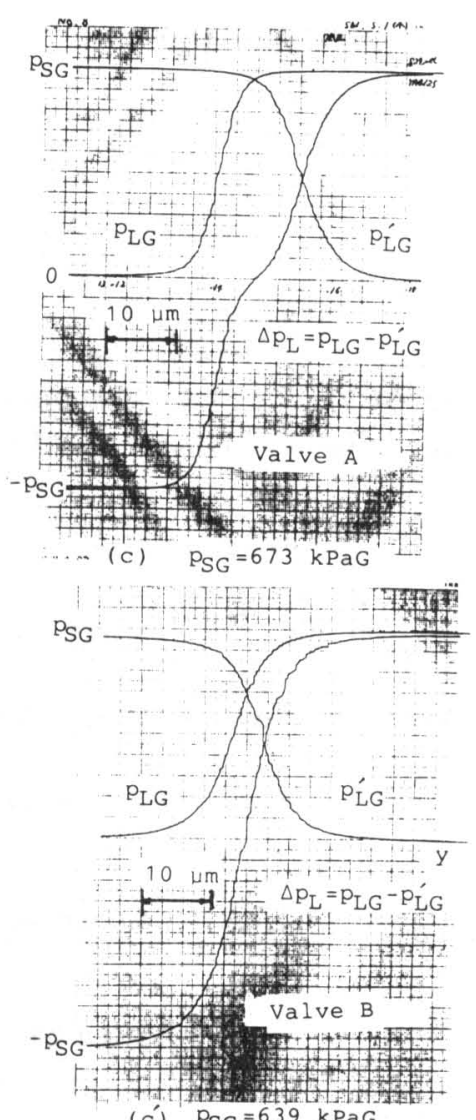

(c) $P_{S G}=639 \mathrm{kPaG}$

Fig. 5 Measured pressure characteristics $p_{L G}$ vs.y, $p^{\prime} L G$ vs.y, and $\Delta \mathrm{p}_{L}$ vs.y of the valves "A" and "B" 


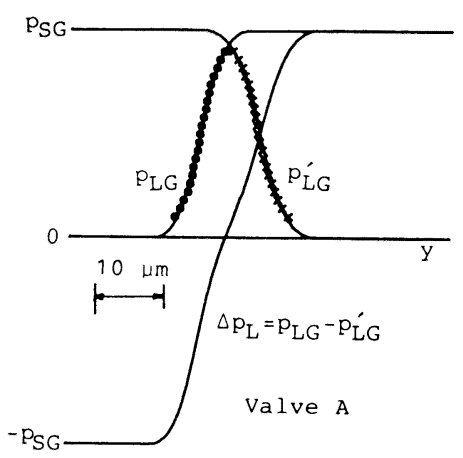

(a) $P_{S G}=45.5 \mathrm{kPaG}$

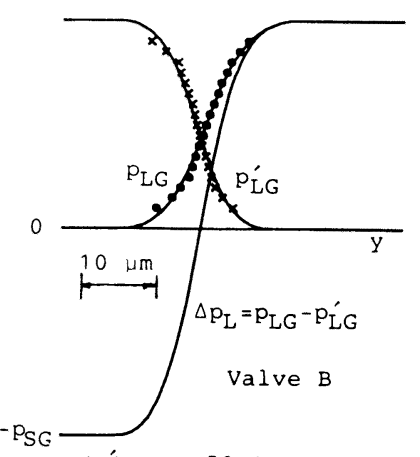

(a) $P_{S G}=50.1 \mathrm{kPaG}$

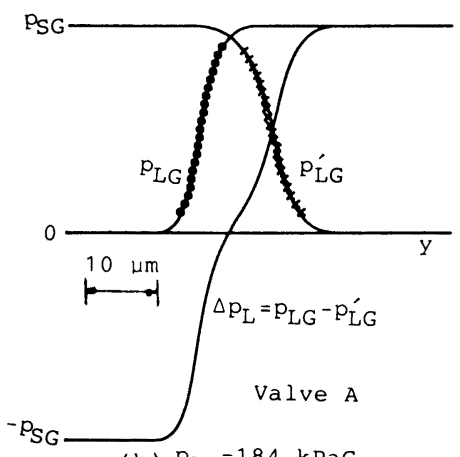

(b) $P_{S G}=184 \mathrm{kPaG}$

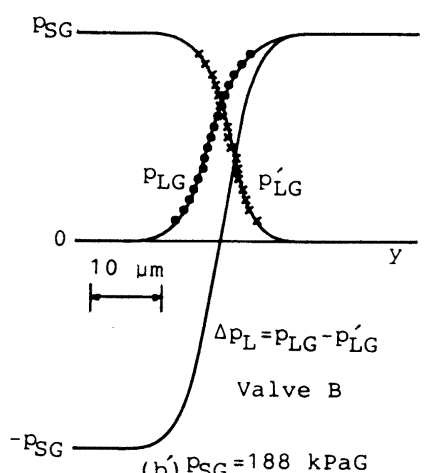

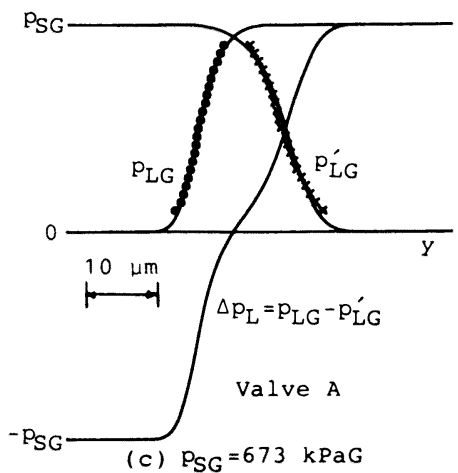

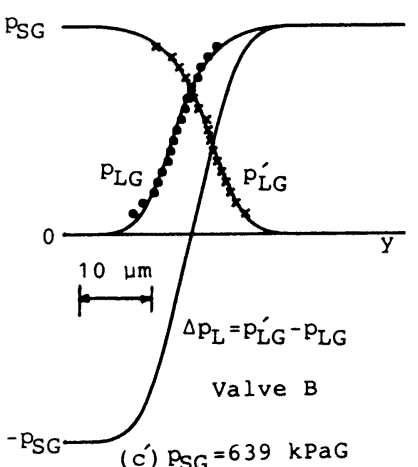

Fig. 6 Comparison of theoretical pressure characteristics with the measured ones of the valves " $A$ " and "B", read from Fig. 5 (Solid lines for theoretical; $\bullet$ for $p_{L G}$ and $\times$ for $p^{\prime}{ }_{L G}$ measured)

よって,

$$
x_{\text {null }}=\frac{x_{0} \Delta^{\prime}+x_{0}^{\prime} \Delta}{\Delta+\Delta^{\prime}}
$$

また，式(15)より

$$
j_{\text {null }}=j_{\text {null }}^{\prime}=\frac{K_{d}\left(x_{\text {null }}-x_{0}\right)}{\Delta}=\frac{K_{d}\left(x_{0}{ }^{\prime}-x_{0}\right)}{\Delta+\Delta^{\prime}}
$$

また $x$ と $x^{\prime} に$ 対する $y$ は次式で与えられる。

$y=K_{d}\left(x-x_{\text {null }}\right)$ または $K_{d}\left(x^{\prime}-x_{\text {null }}\right)$

この式に式(17)，(18)，(27)および(28)を代入すると，次の 式を得る。

$$
\begin{aligned}
& \Delta_{1}=-K_{d}\left(x-\Delta-x_{\text {null }}\right) \\
& \Delta_{2}=K_{d}\left(x_{\Delta}-x_{\text {null }}\right) \\
& \Delta_{1}{ }^{\prime}=K_{d}\left(x^{\prime}-\Delta^{\prime}-x_{\text {null }}\right) \\
& \Delta_{2}{ }^{\prime}=-K_{d}\left(x^{\prime} \Delta^{\prime}-x_{\text {null }}\right)
\end{aligned}
$$

また, 左右の弁の負重合量の不均等指数 $i$ と $i^{\prime}{ }^{3)}$,

$$
i=\frac{\Delta_{1}}{\Delta}-1, \quad i^{\prime}=\frac{\Delta_{1}^{\prime}}{\Delta^{\prime}}-1
$$

とおくことにすると $i=i^{\prime}=j_{\text {null }}$ となる.
Table Indirectly measured lap-unevenesses and underlaps $(\mu \mathrm{m})$ of the valves "A" and "B"

\begin{tabular}{l|c|c|rrr|rrr}
\hline $\begin{array}{l}\text { Valve } \\
\text { name }\end{array}$ & $\begin{array}{c}{ }^{\mathrm{P}_{\mathrm{SG}}} \\
\mathrm{kPaG})\end{array}$ & $i\left(=i^{\prime}\right)$ & $\Delta$ & $\Delta_{1}$ & $\Delta_{2}$ & $\Delta^{\prime}$ & $\Delta_{2}{ }^{\prime}$ & $\Delta_{2}{ }^{\prime}$ \\
\hline \multirow{4}{*}{ "A" } & 45.5 & 0.52 & 9 & 14 & 4 & 11 & 17 & 5 \\
& 90.1 & 0.48 & 9 & 13 & 5 & 12 & 18 & 6 \\
& 184 & 0.44 & 9 & 13 & 5 & 14 & 20 & 8 \\
& 375 & 0.37 & 10 & 14 & 6 & 15 & 21 & 10 \\
& 673 & 0.35 & 11 & 15 & 7 & 16 & 22 & 11 \\
& 963 & 0.35 & 11 & 14 & 7 & 17 & 22 & 11 \\
\hline & 50.1 & -0.097 & 13 & 12 & 15 & 12 & 10 & 13 \\
& 92.2 & -0.093 & 14 & 13 & 15 & 11 & 10 & 12 \\
& 188 & -0.020 & 14 & 13 & 14 & 11 & 11 & 11 \\
& 366 & -0.063 & 14 & 13 & 15 & 13 & 12 & 14 \\
& 639 & -0.075 & 15 & 13 & 15 & 15 & 14 & 16 \\
& 911 & -0.062 & 16 & 15 & 17 & 14 & 13 & 15 \\
\hline
\end{tabular}

以上より，実測した圧力特性（例えばFig. 2 のよう

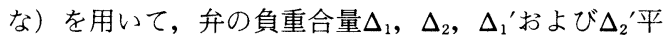

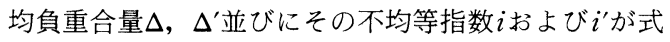
(23), (30)，(33)～(39)より算出される.

\section{3. 等価負重合量の推定例}

\section{1 実験装置及び方法}

2.2 で述べた間接測定法を適用して, 弁形状パラ 
メータ $i, \Delta, \Delta^{\prime}$ 等を測定するために，使用したことの あるサーボ弁を二台用意した。これらのサーボ弁の圧 力特性を測定するために, 両負荷ポートは閉栓し, そ の負荷ポート圧を歪ゲージ式圧力センサで測定した。 弁スプールの一端に座付きばねを挿入し，他端をべア リングボールを介してマイクロメータスピンドルで十 分ゆっくりと押した。そのスプール変位は歪ゲージを 貼ったカンチレバーによって測定した。記録はX-Yレ コーダによって行った.

\section{2 実験結果と考察}

psGが約 $50,180,650 \mathrm{kPaG}$ 場合, 弁Aおよび弁 $\mathrm{B}$ の実測した圧力特性をFig. 5 に示す. Fig. 6 は 2.2 の 方法で求めた結果である. $p_{L G 1}=0.1 p_{S G}, p_{L G m}=0.9 p$ $s G$ とした. 弁Aでは $m=21$, 弁Bでは $m=17$ とした. 求められた $i, \Delta$ 用いて, 算出した理論圧力特性を実 線で示し, 実測データを○, ×印の記号でプロットした ものである，供給圧が低いときは，理論值と実測值は 非常によく一致しているが，供給圧が高くなると，実 測值 $p_{L G}$ および $p_{L G}{ }^{\prime}$ は, 0 近傍で理論值の上側に, $p_{S}$ $G$ 近傍で下側にわずかずれてくる.

弁 $\mathrm{A}$ ，弁 $\mathrm{B}$ のそれぞれ 6 種類のpscに対するデー夕 より，推定された弁形状パラメータをTableにまとめ て示す.この二つの弁については, $p_{s}$ が高くなるにつ れて, 負重合量が増えていくようにみえるが, その大 きさは概ね土 $3 \mu \mathrm{m}$ の範囲であり，スプール変位セン． サの取り付けガタゃスプール・スリーブ間隙等を考え ると，十分実用になる精度と考えられる。

弁Aに付いては， pscが45.5から963kPaGまで変わ ると, 汭 0.52 から 0.35 までかなり変化している.しか し，これはTableの $\Delta_{1}$ がほぼ14 $\mu \mathrm{m}$ であるのに対して， $\Delta$ だけが 9 から $11 \mu \mathrm{m}$ と漸増したため, $i$ が式(37)により
大きく変化したものである.

弁 Bでは，同じ圧力範囲で， $i$ はほとんど同じ值 (0.02〜0.097) になっている.これは， $\Delta_{1}$ とガ同じ ような割合で変化しているためである。

\section{4.むすび}

スプール弁の等価負重合量を定義し, 弁圧力特性よ り間接的に等価負重合量を求める一つの方法を提唱し た.

この間接法により，二種類のサーボ弁の等価負重合 量を間接測定し, 実用上十分な測定精度 $( \pm 3 \mu \mathrm{m})$ の 得られることがわかった。

終わりに, 本研究にご協力いただいた本学学生の小 坂幸生, 李培雨及び川下洋一郎の諸君に深く感謝致し ます。

\section{参 考 文 献}

1) 中野：スプール弁の非対称アンダラップがサーボ モータの駆動力に及ぼす影響, 油圧と空気圧, 5 $-2,86$ (昭和 49 年).

2 ) 林, 大橋：非対称アンダラップ弁を有する油圧 サーボ系の安定性, SICE論文集，22-4，459(昭 和61年).

3 ) 荒木: 不均等負重合案内弁を用いた空気圧案内 弁・シリンダの周波数特性, 第 1 報, 第 2 報, 第 3 報, 油圧と空気圧, 10-1，57；10-6，361 (昭 和54年)：12-4，262（昭和56年).

4 ) 池辺ほか: サーボ機構とその要素, オーム社, 昭 和37年，182または

J.L. Shearer: Fluid Power Control, John Wiley, 1959, 192. 